
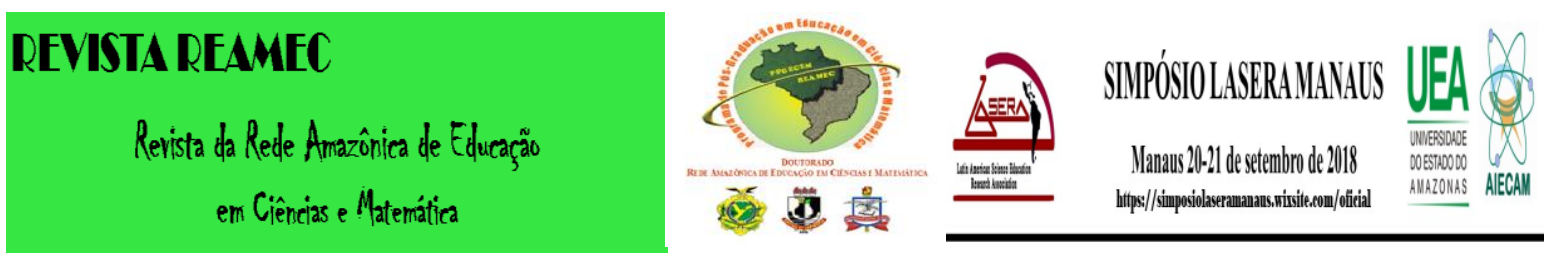

\title{
REFLEXÕES SOBRE O ASPECTO METODOLÓGICO DE TESES E DISSERTAÇÕES EM EDUCAÇÃO E ENSINO DE CIÊNCIAS E MATEMÁTICA
}

\author{
Mateus de Souza Coelho Filho ${ }^{\mathrm{a}}$ \\ Josefina Barrera Kalhil ${ }^{\mathrm{b}}$
}

A R T I C L E I N F O

\author{
Palavras chave: \\ Aspecto metodológico \\ Teses e Dissertações \\ Ciências e Matemática \\ E-mail: \\ ${ }^{\mathrm{a}}$ mcoelho426@gmail.com \\ bjosefinabk@gmail.com
}

\author{
R E S U M O
}

O presente estudo configura-se no resultado do trabalho final da disciplina Pesquisa em Ciências da Educação e em Educação em Ciências, a qual integra a proposta curricular do Programa de Pós-Graduação em Educação em Ciências e Matemática da Rede Amazônica de Educação em Ciências e Matemática-REAMEC. Faz uma abordagem a respeito do aspecto metodológico das produções em cursos de PósGraduação Stricto Sensu. Objetivou analisar o mencionado aspecto em teses e dissertações dos Programas de PósGraduação em Educação e Ensino de Ciências e Matemática. Foi realizado um levantamento quantitativo das produções pesquisadas referente ao aspecto metodológico dos aludidos programas. Posteriormente foi feita a análise do aspecto metodológico empregado nas produções, o qual foi objeto de pesquisa deste estudo. A análise deu-se a partir da leitura do título, resumo e metodologia das produções selecionadas. Os resultados evidenciam que o paradigma ou abordagem que se destaca foi o qualitativo, este esteve presente na maioria de teses e dissertações. Dentre os métodos de procedimento destacam-se o estudo caso, pesquisa documental e pesquisa-ação. Referente as técnicas e instrumentos de coleta de dados, os mais empregados foram a entrevista, observação e questionário, sobre as técnicas de análise de dados destacam-se a análise de conteúdo e análise textual discursiva. Portanto, esses são os elementos metodológicos que estão em relevo nas teses e dissertações analisadas neste estudo, isso evidencia como estes foram, no caso dos trabalhos analisados, e são importantes na medida que contribuirão como suporte metodológico para realização de futuras pesquisas científicas.

\section{INTRODUÇÃO}

Sabemos que toda pesquisa científica precisa de um caminho, de um percurso que direcione e organize o trabalho teórico, epistemológico e principalmente metodológico do pesquisador. Esse configura-se como período em que o pesquisador concretizará o delineamento de sua pesquisa, momento que buscará respostas para seu problema e 
investigação científica, bem como soluções para compreender e evidenciar seu objeto de estudo a partir da coleta e análise dos dados, delineamento que se dará, também, a partir de outros elementos que fazem parte do contexto geral da pesquisa científica.

Este trabalho discuti sobre o aspecto metodológico utilizado nas produções dos pesquisadores dos cursos de Pós-Graduação Stricto Sensu. Nosso objetivo foi analisar o aspecto metodológico utilizado nas teses e dissertações dos Programas de Pós-Graduação em Educação e Ensino de Ciências e Matemática correspondente ao período entre 2005-2017, para chegarmos aos resultados realizamos a leitura do título, resumo e metodologia das teses e dissertações, dando ênfase aos paradigmas/abordagens, técnicas e instrumentos de coleta de dados, bem como as técnicas de analises utilizadas pelos pesquisadores em suas produções acadêmicas e científicas.

O texto organiza-se da seguinte maneira: no primeiro momento ponderamos sobre o traçado metodológico, ou seja, sobre a metodologia deste estudo, como foram coletados os dados, quais instituições e programas foram analisados. No segundo falamos da questão conceitual entre método e metodologia, bem como sua importância no processo de delineamento da pesquisa científica. Posteriormente fazemos a análise dos dados caracterizando o aspecto metodológico das teses e dissertações, por fim tecemos as considerações finais a respeito do trabalho desenvolvido.

Os resultados evidenciam que o paradigma ou abordagem mais utilizado foi $o$ qualitativo, este esteve presente na maioria de teses e dissertações. Dentre os métodos de procedimento destacam-se o estudo caso, pesquisa documental e pesquisa-ação. Referente as técnicas e instrumentos de coleta de dados, os mais empregados foram a entrevista, observação e questionário, sobre as técnicas de análise de dados sobressam-se a análise de conteúdo e análise textual discursiva.

\section{METODOLOGIA}

O presente estudo configura-se no resultado do trabalho final da disciplina Pesquisa em Ciências da Educação e em Educação em Ciências, a qual integra a proposta curricular do Programa de Pós-Graduação em Educação em Ciências e Matemática Rede Amazônica de Educação em Ciências e Matemática-REAMEC. Faz uma abordagem a respeito do aspecto metodológico presente nas teses e dissertações de Programas de Pós-Graduação Stricto Sensu 
na área da Educação e Ensino de Ciências e Matemática no período correspondente entre 2005-2017. Realizamos consultas no banco de dados da biblioteca virtual dos programas. Posteriormente escolhemos os trabalhos em que o aspecto metodológico estava mais evidente e compreensível, pois encontramos trabalhos em que tal aspecto não estava de forma clara e inteligível, nesse caso estes foram excluídos da análise, sendo selecionados para a mesma somente aqueles com metodologia clara, objetiva, evidente e que discutiam sobre a formação de professores e/ou ensino de Matemática, isto porque nosso projeto de tese objetivava discutir sobre tais questões.

Foram selecionados ao todo $66(100 \%)$ teses e dissertações de 12 Programas de PósGraduação Stricto Sensu. Desse total tivemos $(27,30 \%)$ de teses e $(72,70 \%)$ de dissertações. Foram escolhidos para análise somente 42 trabalhos $(63,70 \%)$ do total selecionado. A escolha deu-se pelo fato do aspecto metodológico encontrar-se de forma mais evidente e objetiva, além deste estar voltado para a formação de professores e/ou ensino de Matemática, uma vez que nosso projeto de tese, mesmo que provisoriamente, pretende discutir essa temática. Desses 42, agora representando $100 \%$ dos trabalhos, foi evidenciado $(26,20 \%)$ de teses e $(73,80 \%)$ de dissertações. Foi realizada a leitura do título, resumo e metodologia das teses e dissertações selecionadas para análise. Os trabalhos têm periodicidade de 2005 a 2017, encontram-se no banco da biblioteca virtual de teses e dissertações dos Programas de PósGraduação Stricto Sensu na área de Educação e Ensino de Ciências e Matemática.

\section{RESULTADOS E DISCUSSÃO}

\subsection{Método e metodologia: conceitos, reflexões e importância na pesquisa científica}

Falar do aspecto metodológico no desenvolvimento de uma pesquisa é fazer referência sobres seus procedimentos, caminhos e itinerários como condição sinequa non para buscar repostas, compreender o fenômeno investigado ou encontrar soluções científicas para a pesquisa e a própria ciência. $\mathrm{O}$ aspecto metodológico é fundamental para o pesquisador conduzir o processo investigativo, é elemento que o direciona no caminhar epistemológico no desenvolvimento da pesquisa científica. Não é nossa finalidade caracterizar este aspecto como sendo o central ou primordial do processo de pesquisa, pelo contrário, tal aspecto deve estar em consonância e diálogo com os outros elementos deste processo, a metodologia configura- 
se como parte desta e não como todo. Nesse sentido, todos os elementos que a compõe precisam ter harmonia recíproca para que se desenvolva uma pesquisa clara, objetiva, coesa e coerente.

De acordo com Ghedin e Franco (2011) o método de um projeto de pesquisa indica a direção por onde ela caminhará, mas é somente depois do trajeto que se pode ter uma descrição mais rica e detalhada do processo de investigação. O método é sempre uma perspectiva de onde se parte que permite pressentir a chegada a algum lugar. Ele propicia o vislumbre de um percurso antes de chegar aos detalhamentos do caminho. Enseja a caminhada em determinada rota. É isso que torna a pesquisa e o conhecimento científico possíveis. O método constitui o fundamento de toda e qualquer teoria. Esta resulta de um método que tornou sua elaboração possível. É certo considerar que a mudança de perspectiva metodológica interfere no processo e no resultado da investigação. O método é aquilo que possibilita a interpretação, mediante algum instrumento, do objeto que possui mais de um significado.

Trujillo Ferrari (1982) compreende que o método é a maneira de se proceder ao longo de um caminho. Na ciência, os métodos constituem os instrumentos básicos que dispõem em sistemas e traçam de modo ordenado a forma de proceder do cientista para alcançar um objetivo ao longo de um percurso. Galliano (1986) define método como o conjunto de etapas, ordenadamente dispostas, a serem vencidas na investigação da verdade, no estudo de uma ciência ou para alcançar determinado fim. Nesse sentido o método é fundamental, pois permite que o pesquisador oriente, auxilie e descreva de forma sistemática, rigorosa, metódica e flexível os propósitos e os objetivos que pretende alcançar no estudo de determinado fenômeno.

Atrelada a questão do método está a metodologia, a qual caracteriza-se como conjunto de métodos que ajudam no desenvolvimento e que objetivam desvelar e compreender o fenômeno alvo da pesquisa, bem como produzir conhecimento. Para Fonseca (2002) a metodologia é o estudo da organização, dos caminhos a serem percorridos, para se realizar uma pesquisa ou um estudo, ou para se fazer ciência. Etimologicamente, significa o estudo dos caminhos, dos instrumentos utilizados para fazer uma pesquisa científica. Prodanov e Freitas (2013) afirmam que a metodologia consiste em estudar, compreender e avaliar os vários métodos disponíveis para a realização de uma pesquisa, em um nível 
aplicado, examina, descreve e avalia métodos e técnicas de pesquisa que possibilitam a coleta e o processamento de informações, visando ao encaminhamento e a resolução de problemas e/ou questões de investigação. A metodologia é a aplicação de procedimentos e técnicas que devem ser observados para construção do conhecimento, com o propósito de comprovar sua validade e utilidade nos diversos âmbitos da sociedade, se interessa pela validade do caminho escolhido para se chegar ao fim proposto pela pesquisa.

A metodologia é o caminho que conduz o pesquisador na busca da verdade, ainda que provisória, que direciona o mesmo a construir um conhecimento científico pautado no rigor que a ciência exige, é o elemento que dá sustentação teórica e prática ao pesquisador na busca de alcançar ou se aproximar dos objetivos idealizados. É por meio desta que se estreita na prática investigativa o planejamento inicial da pesquisa. Me arrisco a dizer que não existe pesquisa sem metodologia, uma vez que esta é o caminho e o traçado fundamental que conduz o pesquisador no seu caminhar epistemológico e metodológico na busca da verdade científica. É por meio desta que se desenvolve a pesquisa, pois além de fazer o desenho metodológico daquela é o momento que o pesquisador materializa de forma sistemática e rigorosa a coleta de dados que vão sustentar e fundamentar sua análise a partir do que foi coletado enquanto objeto de análise. A metodologia é elemento imprescindível numa pesquisa na medida que conduz o pesquisador em seu itinerário investigativo a enveredar por um caminho que busca desvelar a realidade por meio da inquietude daquele que está na condição de pesquisador e construtor de um conhecimento científico pautado no rigor e sistematização metodológica.

\subsection{Caracterização do aspecto metodológico de teses e dissertações}

Neste estudo foram selecionados 66 (100\%) teses e dissertações de 12 Programas de Pós-Graduação. Desse total tivemos (27,30\%) de teses e (72,70\%) de dissertações. Desses 42 , agora representando $100 \%$ dos trabalhos, constatamos $(26,20 \%)$ de teses e $(73,80 \%)$ de dissertações. Foi realizada a leitura do título, resumo e metodologia das teses e dissertações selecionadas para análise. Os trabalhos têm periodicidade de 2005 a 2017, encontram-se no banco da biblioteca virtual de teses e dissertações dos Programas de Pós-Graduação Stricto Sensu na área de Educação e Ensino de Ciências e Matemática. Os trabalhos produzidos nos referidos Programas de Pós-Graduação encontram-se distribuídos da seguinte maneira:

Quadro 01: Programas de Pós-Graduação e universidades analisadas neste estudo.

Revista REAMEC, Cuiabá - MT, V. 6, n. Especial, dez 2018, ISSN: 2318-6674

Revista do Programa de Doutorado da Rede Amazônica de Educação em Ciências e Matemática

http://periodicoscientificos.ufmt.br/ojs/index.php/reamec 
Revista ta Rede Amazôniza de Eduração

em Ciências e Materática

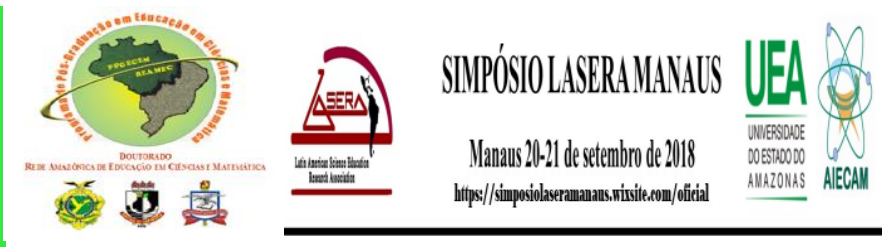

\begin{tabular}{|c|c|c|}
\hline Programa & Vinculação & $\begin{array}{c}\text { Teses e } \\
\text { dissertações }\end{array}$ \\
\hline $\begin{array}{c}\text { Programa de Pós-Graduação em Ensino } \\
\text { de Ciências e Matemática }\end{array}$ & Universidade Cruzeiro do Sul-SP & 02 \\
\hline $\begin{array}{l}\text { Programa de Pós-Graduação em Ensino } \\
\text { de Ciências e Educação Matemática }\end{array}$ & $\begin{array}{l}\text { Universidade Estadual de } \\
\text { Londrina }\end{array}$ & 05 \\
\hline $\begin{array}{c}\text { Programa de Pós-Graduação em Ensino } \\
\text { de Ciências e Matemática }\end{array}$ & $\begin{array}{c}\text { Centro Universitário Franciscano } \\
\text { Santa Maria-RS } \\
\end{array}$ & 02 \\
\hline $\begin{array}{c}\text { Programa de Pós-Graduação em Ensino } \\
\text { de Ciências e Matemática }\end{array}$ & Universidade Federal de Alagoas & 01 \\
\hline $\begin{array}{l}\text { Programa de Pós-Graduação em Ensino } \\
\text { de Ciências e Matemática da }\end{array}$ & $\begin{array}{l}\text { Universidade Luterana do Brasil } \\
\text { ULBRA-Canoas-RS }\end{array}$ & 03 \\
\hline $\begin{array}{c}\text { Programa de Pós-Graduação em Ensino } \\
\text { de Ciências e Matemática }\end{array}$ & Universidade Estadual da Paraíba & 07 \\
\hline $\begin{array}{l}\text { Programa de Pós-Graduação em Ensino } \\
\text { de Ciências e Matemática }\end{array}$ & $\begin{array}{l}\text { Universidade Federal de } \\
\text { Uberlândia }\end{array}$ & 01 \\
\hline $\begin{array}{l}\text { Programa de Pós-Graduação em Ensino } \\
\text { de Matemática }\end{array}$ & $\begin{array}{l}\text { Universidade Federal do Rio } \\
\text { Grande do Sul }\end{array}$ & 06 \\
\hline $\begin{array}{c}\text { Programa de Pós-Graduação em Ensino } \\
\text { de Ciências e Matemática }\end{array}$ & Universidade Federal do Acre & 02 \\
\hline $\begin{array}{c}\text { Programa de Pós-Graduação em } \\
\text { Educação em Ciências e Matemática }\end{array}$ & Universidade Federal de Goiás & 09 \\
\hline $\begin{array}{c}\text { Programa de Pós-Graduação em } \\
\text { Educação em Ciências e Matemática }\end{array}$ & Universidade Federal do Pará & 04 \\
\hline
\end{tabular}

Fonte: Coelho Filho, 2017.

Dos trabalhos analisados referente ao paradigma/abordagem, evidenciamos que $97,7 \%$ utilizaram o paradigma qualitativo, 2,3\% o paradigma misto, ou seja, quantitativo-qualitativo e nenhum utilizou o paradigma quantitativo. Podemos perceber que 97,7\% escolheram o paradigma qualitativo para desenvolver suas pesquisas, compreende-se que o objeto de pesquisa destes pesquisadores caracterizou tal escolha. Para Creswell (2010) a pesquisa qualitativa é um meio para explorar e atender o significado que os indivíduos ou os grupos atribuem a um problema social ou humano. O processo de pesquisa envolve as questões e os procedimentos que emergem, os dados tipicamente coletados no ambiente do participante, a análise dos dados indutivamente construída a partir das particularidades para os temas gerais e as interpretações feitas pelo pesquisador acerca do significado dos dados.

Alami, Desjeux e Moussaoui-Garabuau (2010) afirmam que as abordagens qualitativas são metodologicamente compreensivas, mais do que criticar ou denunciar elas buscam compreender a lógica social de cada ator. A pesquisa qualitativa permite-nos compreender o 
fenômeno investigado intrinsecamente, tentando, não generalizar os fatos, mas apreender os fenômenos objeto de investigação por meio das informações e dados coletados.

Outro paradigma que os investigadores utilizaram, porém com menor frequência foi o misto, ou seja, o quantitativo-qualitativo, este paradigma foi utilizado em 2,3\% dos trabalhos produzidos. O método misto de pesquisa é aquele que se refere ao estudo investigativo que utiliza estratégias ou abordagens ora quantitativas ora qualitativas como premissa para buscar respostas ou explicações ao problema científico, confirmar ou refutar hipóteses. Pelos que podemos analisar estes trabalhos utilizaram e agregaram elementos dos dois paradigmas como condição para evidenciar seu objeto de estudo. Este prima pela conjugação de aspectos tanto do paradigma qualitativo quanto do quantitativo para obter e ampliar as informações a respeito do objeto investigado nas abordagens investigativas dos pesquisadores.

Os métodos mistos combinam os métodos predeterminados das pesquisas quantitativas com métodos emergentes das qualitativas, assim como questões abertas e fechadas, com formas múltiplas de dados contemplando todas as possibilidades, incluindo análises estatísticas e análises textuais. Neste caso, os instrumentos de coleta de dados podem ser ampliados com observações abertas, ou mesmo, os dados censitários podem ser seguidos por entrevistas exploratórias com maior profundidade. No método misto, o pesquisador baseia a investigação supondo que a coleta de diversos tipos de dados garanta um entendimento melhor do problema pesquisado. Por isso, é mais do que uma simples coleta e análise dos dois tipos de dados; envolve também auso das duas abordagens em conjunto, de modo que a força geral de um estudo seja maior do que a da pesquisa qualitativa ou quantitativa isolada (CRESWELL, 2010).

Por fim, referente aos paradigmas ou abordagens utilizadas nos trabalhos produzidos, nenhum trabalho utilizou do paradigma quantitativo, entretanto isso não quer dizer que este não seja importante nas e para as pesquisas científicas, os objetos de pesquisa averiguados, bem como sua escolha metodológica não dialogaram de forma recíproca a ponto dos pesquisadores não optarem por este paradigma em suas empreitadas de investigação. Pelo contrário este paradigma é muito importante nos construtos investigativos, tem uma relevância significativa para a ciência de um modo geral, há percursos investigativos que evidenciam seu objeto de pesquisa ou buscam respostas aos problemas científicos única e exclusivamente por meio deste paradigma, 
os resultados só podem ser corroborados ou demonstrados por meio do quantitativo.

Quanto aos métodos de procedimentos utilizados, concluímos que houve uma variedade maior se compararmos com os paradigmas ou abordagens utilizadas nas teses e dissertações dos programas.

Nos trabalhos produzidos pelos pesquisadores dos programas analisados, evidenciamos que 47,8\% utilizaram o estudo de caso, escolheram um caso particular para desvelar e compreender o objeto alvo da investigação científica. O caso escolhido para a pesquisa deve ser significativo e bem representativo, de modo a ser apto a fundamentar uma generalização para situações análogas, autorizando inferências. Os dados devem ser coletados e registrados com o necessário rigor e seguindo todos os procedimentos da pesquisa de campo. Devem ser trabalhados, mediante análise rigorosa, e apresentados em relatórios qualificados Severino (2007).

O estudo de caso consiste em coletar e analisar informações sobre determinado indivíduo, uma família, um grupo ou uma comunidade, a fim de estudar aspectos variados de sua vida, de acordo com o assunto da pesquisa. É um tipo de pesquisa qualitativa e/ou quantitativa, entendido como uma categoria de investigação que tem como objeto o estudo de uma unidade de forma aprofundada, podendo tratar-se de um sujeito, de um grupo de pessoas, de uma comunidade etc. São necessários alguns requisitos básicos para sua realização, entre os quais, severidade, objetivação, originalidade e coerência Prodanov e Freitas (2013).

$38,1 \%$ dos pesquisadores escolheram a pesquisa documental em seus trabalhos, uma vez que seus objetos de investigação se delinearam nessa perspectiva. É um tipo de pesquisa que tem como fonte documentos em sentido amplo, nessa pesquisa os documentos extrapolam os impressos, considera-se documento objeto de análise filmes, jornais, revistas, documentos legais, fotos, gravações, em fim todo documento que ainda não passou pelo crivo rigoroso e analítico para ser alvo e objeto de estudo do pesquisador.

9,6\% dos pesquisadores utilizaram a pesquisa bibliográfica em suas produções. É um tipo de pesquisa que é realizada a partir de trabalhos já produzidos por outros pesquisadores. De certa forma os trabalhos que foram e serão produzidos necessitam de uma pesquisa nessa perspectiva uma vez que todo trabalho de cunho científico precisa de uma fundamentação teórica, de um aporte teórico que sustente, a partir de pesquisa bibliográfica, o trabalho que está sendo construído, objetivando colocar o investigador na rota epistemológica com os 
outros trabalhos já produzidos referentes a temática objeto de investigação. A pesquisa bibliográfica é aquela que se realiza a partir do registro disponível, decorrente de pesquisas anteriores, em documentos impressos, como livros, artigos, teses etc. Utiliza-se de dados ou de categorias teóricas já trabalhados por outros pesquisadores e devidamente registrados. Os textos tornam-se fontes dos temas a serem pesquisados. $\mathrm{O}$ pesquisador trabalha a partir das contribuições dos autores dos estudos analíticos constantes nos textos Severino (2007).

Entretanto é importante distinguir a pesquisa documental da pesquisa bibliográfica. Gil (2008) destaca como principal diferença entre esses tipos de pesquisa a natureza das fontes de ambas as pesquisas. Enquanto a pesquisa bibliográfica se utiliza fundamentalmente das contribuições de vários autores sobre determinado assunto, a pesquisa documental baseiase em materiais que não receberam ainda um tratamento analítico ou que podem ser reelaborados de acordo com os objetivos da pesquisa.

No que se refere as técnicas e instrumentos de coleta de dados evidenciamos que os mais utilizados foram a observação, entrevista e questionário, com menor frequência encontram-se o grupo focal, notas de campo. Mesmo com pouca utilização estes últimos têm sua relevância e são importantes para e no processo investigativo.

A técnica mais utilizada foi a entrevista, esteve presente em $85,8 \%$ das teses e dissertações analisadas. A entrevista como técnica de coleta de dados se correlaciona com a paradigma qualitativo, configura-se como encontro entre pesquisador e pesquisados, o primeiro com o intuito de obter informações e dados junto aos segundos, sempre tendo como parâmetro o objeto de pesquisa e o fenômeno a ser investigado. O pesquisador pode utilizar em sua pesquisa a entrevista estruturada, não estruturada, focalizada, não dirigida e na forma de painel, o objeto da pesquisa terá papel significativo na definição do processo de coleta dos dados e informações necessários a mesma. A entrevista, como técnica, é muito importante na coleta de dados porque permite ao pesquisador obter informações de extrema relevância, as quais vão dar suporte informacional para o pesquisador fazer sua análise Coelho Filho e Gonzaga (2013).

A observação esteve presente em $62 \%$ das teses e dissertações analisadas. É uma técnica, assim como outras, muito importante na coleta de dados, pois o pesquisador observa e registra os sujeitos e seu ambiente. Vale ressaltar que esta técnica muitas vezes necessita de outras para que o pesquisador compreenda seu objeto de pesquisa. Pode acontecer de forma 
sistemática, assistemática, individual, coletiva, participante, não-participante. A observação pode ser realizada de várias formas, ou seja, pode ser individual ou em grupo; estruturada e não-estruturada, participante e não-participante, em fim o pesquisador poderá utilizá-la de diversas maneiras, seu objeto de investigação norteará tal escolha. A observação é uma técnica de coleta de dados para conseguir informações e utiliza os sentidos na obtenção de determinados aspectos da realidade. Não consiste em apenas ver e ouvir, mas também em examinar fatos ou fenômenos que deseja estudar. Desempenha papel importante nos processos observacionais, no contexto da descoberta, e obriga o observador a um contato mais direto com a realidade Lakatos e Marconi (2010).

Outra técnica utilizada nas produções foi o questionário, esteve presente em 40,5\% dos trabalhos analisados, foi o instrumento que os pesquisadores utilizaram para coletar dados e informações junto aos pesquisados. É um tipo de instrumento em que o pesquisador elabora perguntas ordenadas para que o informante responda de forma escrita sem a presença do primeiro. Pode-se utilizar perguntas de cunho aberto, fechado ou de múltipla escolha, essas dependem do que o pesquisador pretende saber dos informantes, bem como se atende ou responde seu problema científico. O questionário é considerado um importante instrumento de pesquisa por fornecer subsídios reais do universo ou amostra pesquisada. A elaboração de um questionário requer que o pesquisador conheça a realidade a ser pesquisada. A elaboração das questões deve estar fundamentada no problema formulado, na hipótese e teoria pertinentes ao tema pesquisado Oliveira (2007).

$4,8 \%$ dos pesquisadores utilizaram o grupo focal como técnica para coletar os dados, para estes a forma de coletar os mesmos deu-se por meio da construção de um grupo para obter informações para suas pesquisas. O grupo focal é uma técnica que permite ao pesquisador reunir um grupo de pessoas com o intuito de saber informações sobre determinado tema, o qual deve estar em consonância com os objetivos e objeto de pesquisa. $\mathrm{O}$ grupo focal permite fazer emergir uma multiplicidade de pontos de vista e processos emocionais, pelo próprio contato de interação criado, permitindo a captação de significados que, com outros meios, poderiam ser difíceis de se manifestar. $\mathrm{O}$ trabalho com grupos focais permite compreender processos de construção da realidade por determinados grupos sociais, compreender práticas cotidianas, ações e reações a fatos e eventos, comportamentos e atitudes, constituindo-se uma técnica importante para o conhecimento das representações, 
percepções, crenças, hábitos, valores, restrições, preconceitos, linguagens e simbologias prevalentes no trato de uma dada questão por pessoas que partilham alguns traços em comum, relevantes para o estudo do problema visado Gatti (2005).

$4,8 \%$ dos pesquisadores utilizaram as notas de campo como técnica para coletar os dados. A nota de campo configura-se como estada em campo do pesquisador tomando nota do observado, registrando por meio das observações os acontecimentos, as experiências, as vivencias dos pesquisados de forma sistemática e intensiva. Após esse momento o pesquisador descreve e registra o observado. É valido ressaltar que essa tomada de nota, registro e descrição não é algo simples, requer do pesquisador habilidades importantes para que não perca o foco de seu objeto de pesquisa, isso porque é desse momento que depende a análise desta, uma vez perdendo o foco os resultados podem não corresponder ao delineamento inicial da pesquisa. De acordo com Bogdan e Biklen (1994) as notas de campo constituem o relato escrito daquilo que o investigador ouve, vê, experiencia e pensa no decurso da recolha.

2,4\% dos pesquisadores utilizaram a história de vida para desvelar e compreender seu objeto de estudo. Esta é uma forma de captar informações e dados necessários junto aos sujeitos e participantes da pesquisa. É um método que recorre a entrevista como técnica para dar validade científica aos dados e informações relatadas pelos informantes no processo de pesquisa, é uma forma de cientificar esses dados e informações. Nesta perspectiva percebe-se o caráter subjetivo desta proposta investigativa, pois os informantes relatam oralmente sobre determinado assunto, tema, visão de mundo, em fim algo que o pesquisador pretende investigar e que esteja em consonância com seu objeto de investigação. Neste tipo de pesquisa o que interessa é o ponto de vista, os relatos dos informantes e não a subjetividade do pesquisador, lógico que em dado momento o segundo terá que dar um tratamento específico e sistemático, bem como fazer uma análise crítica desses dados, fará isso a partir dos relatos externados pelos informantes. Nesse sentido a história de vida coleta as informações da vida de um ou vários informantes. Pode assumir formas variadas: autobiografia, memorial, crônicas, em que se possa expressar as trajetórias pessoais dos sujeitos Severino (2007). De acordo com Thiollent (1982) a história de vida é, geralmente, extraída de uma ou mais entrevistas denominadas entrevistas prolongadas, nas quais a interação entre pesquisador e pesquisado se dá de forma contínua. O entrevistador se mantém em uma situação flutuante 
que permite estimular o entrevistado a explorar o seu universo cultural, sem questionamento forçado.

2,4\% dos pesquisadores utilizaram a história oral como procedimento técnico em suas produções acadêmicas. Entenderam que seu objeto de pesquisa precisava deste método para clarificar suas inquietações científicas e epistemológicas, pois seus objetos enveredaram a partir do desenho investigativo por essa perspectiva. A história oral assim como a história de vida são métodos que objetivam, por meio dos relatos dos informantes, trazer à tona fatos vividos, presenciados, assistidos por quem os vivenciou, pois centra-se no ser humano, naquilo que a memória consegue reter levando em consideração a capacidade que o próprio ser humano, enquanto testemunha viva, tem de sedimentar em sua memória e intelecto os fatos por ele vivenciados. A história oral pode ser entendida como um método de pesquisa (histórica, antropológica, sociológica) que privilegia a realização de entrevistas com pessoas que participaram de, ou testemunharam acontecimentos, conjunturas, visões de mundo, com a forma de se aproximar do objeto de estudo. Trata-se de estudar acontecimentos históricos, instituições, grupos sociais, categorias profissionais, movimentos, etc. Alberti (1990).

Quanto as técnicas de análise dos dados, os trabalhos produzidos apresentam basicamente análise de conteúdo de analise textual discursiva. A análise de dados é o processo de busca e de organização sistemática de transcrições de entrevistas, de notas de campo e de outros materiais que foram sendo acumulados, com o objetivo de aumentar sua própria compreensão desses mesmos materiais, e de permitir apresentar aos outros o que encontrou. A análise envolve o trabalho com os dados, sua organização, divisão em unidades, síntese, procura de padrões, descoberta dos aspectos importantes e do que deve ser aprendido e a decisão do que vai ser transmitido aos outros Bogdan e Biklen (1994).

Segundo Moraes e Galiazzi (2011) o processo de análise consiste num ir-e-vir, agrupar e desagrupar, construir e desconstruir. O processo é de constantes retomadas, avaliando-se com frequência tudo o que já foi realizado para refazê-lo ou melhorá-lo.

Sobre a análise de conteúdo, constatamos que 50,0\% dos pesquisadores a utilizaram em suas teses e dissertações como técnica para analisar os dados. É uma técnica que a partir dos dados coletados, o pesquisador vai categorizá-los, o faz a partir das semelhanças encontradas nos dados. Segundo Bardin (1979) a análise de conteúdo é um conjunto de técnicas de análise de comunicação visando obter, por procedimentos sistemáticos e 
objetivos de descrição do conteúdo das mensagens, indicadores (quantitativos ou não) que permitam a inferência de conhecimentos relativos às condições de produção/recepção destas mensagens. De acordo com Moraes e Galiazzi (2011) a análise de conteúdo investe tanto em descrição como em interpretação. A descrição, nesta perspectiva de análise, é uma etapa muito importante e necessária. As categorias construídas no processo de análise de algum modo envolvem tanto descrição como interpretação, de forma que a conjugação da primeira e da segunda façam emergir dos sujeitos compreensões a respeito do objeto investigado.

Quanto a segunda técnica de análise de dados utilizada, ou seja, a análise textual discursiva, somente $26,2 \%$ das teses e dissertações a empregaram. A análise textual discursiva opera com significados construídos a partir de um conjunto de textos. Os materiais textuais constituem significantes a que o analista precisa atribuir sentidos e significados. A análise textual concretiza-se a partir de um conjunto de documentos denominado "corpus". Este representa as informações da pesquisa e para a obtenção de resultados válidos e confiáveis requer uma seleção e delimitação rigorosa. $O$ "corpus" da análise textual, sua matéria-prima, é constituído essencialmente de produções textuais. Os textos são entendidos como produções linguísticas, referentes a determinado fenômeno e originadas em um determinado tempo e contexto. São vistos como produções que expressam discursos sobre diferentes fenômenos e que podem ser lidos, descritos e interpretados, correspondendo a uma multiplicidade de sentidos que a partir deles podem ser construídos Moraes e Galiazzi (2011).

Os autores afirmam ainda que os textos que compõem o "corpus" da análise podem tanto ser produzidos especialmente para a pesquisa quanto podem ser documentos já existentes previamente. No primeiro grupo integram-se transcrições de entrevistas, registros de observação, depoimentos produzidos por escrito, assim como anotações e diários diversos. O segundo grupo pode ser constituído de relatórios, publicações de várias naturezas, tais como editoriais de jornais e revistas, resultados de avaliações, atas de diversos tipos, entre muitos outros. O restante das produções analisadas não apresentava de forma clara e compreensível de que maneira foi feita a análise dos dados, nesse sentido não tivemos elementos para fazer realizar tal análise. 


\section{CONSIDERAÇÕES FINAIS}

Em todo trabalho de pesquisa os investigadores necessitam delinear em seus itinerários investigativos um caminho, um percurso a ser seguido, esse caminho configura-se no aspecto metodológico, este por sua vez intenta buscar respostas para as inquietações e problemas científicos dos pesquisadores. Não obstante, este estudo objetivou analisar o aspecto metodológico de 42 teses e dissertações de 12 Programas de Pós-Graduação em Educação e Ensino de Ciências e Matemática no período correspondente entre os anos de 2005 a 2017.

Após seleção e análise dos trabalhos, constatamos que referente aos paradigmas a grande maioria utilizou o qualitativo, este foi amplamente empregado nos trabalhos produzidos nos referidos programas, compreendemos que os objetos e os objetivos de pesquisa dos investigadores os levaram a fazer tal escolha, pois o paradigma qualitativo, assim como outros, configura-se como caminho que os guiou no sentido de apreender, no decurso investigativo, seu objeto ou fenômeno de pesquisa. Outro paradigma utilizado nas teses e dissertações foi o misto, ou seja, o quali-quantitativo, onde uma minoria de pesquisadores o utilizou para compreender seu objeto de pesquisa. Entenderam que para o êxito de suas pesquisas precisaram fazer uso dos dois paradigmas. Mesmo sendo pouco utilizado é um paradigma que aos poucos vem ganhando espaço nas pesquisas científicas, pois muitas vezes os pesquisadores necessitam ora do paradigma qualitativo ora do quantitativo. Um terceiro paradigma que é conhecido dos pesquisadores é o quantitativo, entretanto não foi utilizado em nenhuma tese e dissertação analisada dos programas de PósGraduação Stricto Sensu objeto deste estudo.

No que se refere aos métodos de procedimentos, evidenciamos que o mais utilizado pelos pesquisadores foi o estudo de caso, pois precisaram estudar um caso específico como delineamento de e em suas pesquisas. O segundo foi a pesquisa documental, ou seja, tiveram que fazer consultas e análises em documentos como fonte de dados para desvelar seus objetos de estudo. O terceiro foi a pesquisa-ação, tiveram que no desenvolvimento da pesquisa propor uma (s) ação (ões) como condição não só para desvelar o objeto de pesquisa como também propor, a partir da coleta de dados, mudanças nas realidades investigadas. O quarto foi a pesquisa bibliográfica, de certa forma é um tipo de pesquisa que o pesquisador utiliza para Revista REAMEC, Cuiabá - MT, V. 6, n. Especial, dez 2018, ISSN: 2318-6674 Revista do Programa de Doutorado da Rede Amazônica de Educação em Ciências e Matemática http://periodicoscientificos.ufmt.br/ojs/index.php/reamec 
sustentar teoricamente sua pesquisa. As pesquisas etnográfica, participante e narrativa, foram utilizadas com menor frequência, mesmo com pouca utilização são importantes para desvelar objetos e problemas científicos, no caso dos trabalhos analisados os mesmos não necessitaram com maior frequência destas, entretanto sabemos que são significativas para produzir conhecimento científico.

Quanto as técnicas e instrumentos de coleta de dados utilizados nos trabalhos, constatamos que a maioria dos pesquisadores utilizou a entrevista, está serviu para que os mesmos coletassem informações junto aos pesquisados, a qual foi de suma importância para que respondessem as inquietações dos pesquisadores. É uma técnica muito recorrente na produção dos trabalhos acadêmicos porque permite obter dados de forma precisa, sistemática e organizada. Outra técnica utilizada nos trabalhos foi a observação, técnica que foi e é importante porque consentiu aos pesquisadores observarem o fenômeno no local onde o mesmo aconteceu, embora certas vezes o pesquisador necessite de outras técnicas e instrumentos para obter o máximo de informações e dados para ter elementos para realizar sua análise, sem dados não há como fazer análise e chegar as conclusões ou considerações finais. O questionário aparece como terceiro instrumento mais utilizado nas pesquisas analisadas, é um instrumento que os pesquisadores utilizaram como condição para ampliar a obtenção de dados, entretanto assim como a observação também em certos momentos necessita de outras técnicas para aprofundamento na coleta dos dados.

A quarta técnica com maior utilização foram as notas de campo, as quais permitiram que pesquisadores tomassem notas e registrassem no campo de ação as informações necessárias para posterior análise destas. Outra técnica utilizada nos trabalhos foi o grupo focal, técnica bastante significativa na medida que os pesquisadores necessitaram dialogar com mais de um sujeito de pesquisa ao mesmo tempo, permitiu que obtivessem vários pontos de vistas sobre seus objetos de pesquisa de forma convergente e divergente simultaneamente. Outras duas técnicas que os pesquisadores necessitaram utilizar em seus trabalhos foi a história oral e de vida, foram duas técnicas importantes porque possibilitaram que os informantes relatassem suas experiências, suas histórias de forma cronológica aos primeiros, estes por sua vez as registraram como elemento para suas respectivas análises. Em síntese estas foram as técnicas e instrumentos de coleta de dados encontrados nas teses e dissertações analisadas, vale ressaltar que estas se configuram como importantes para que os 


\section{REVISTA REAMEC}

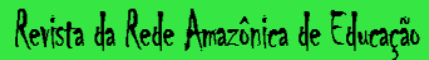

em Ciênciass e Matemática
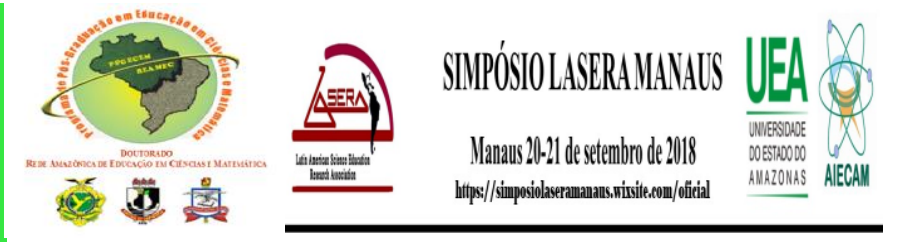

pesquisadores coletem os dados para posterior análise dos mesmos.

Com relação as técnicas de análise de dados percebemos que os pesquisadores utilizaram somente duas, a análise de conteúdo e a análise textual discursiva. A primeira foi utilizada na maioria das teses e dissertações, pois os dados coletados pelos pesquisadores por meio das técnicas e instrumentos precisaram ser categorizados para melhor construção das análises, para chegarem as categorias tiveram que encontrar semelhanças ou similaridade nos dados para em seguida realizar a categorização. Outra técnica de análise de dados utilizada foi análise textual discursiva, esta foi utilizada com menor incidência com relação a primeira, os pesquisadores a utilizaram a partir do agregado de documentos que constituem o corpus da e na pesquisa, este configura-se como conjunto de informações que compõe matéria prima para análise dados. O que os pesquisadores fizeram foi justamente dá um tratamento analítico e rigoroso as informações obtidas. De modo sintético essas foram as duas técnicas de análise de dados. É oportuno frisar que existem outras, entretanto as que foram encontradas nos trabalhos analisados sintetizam-se nas mencionas anteriormente.

É valido observar que mesmo realizando a análise de forma separada dos paradigmas, técnicas e instrumentos, houve trabalhos que utilizaram mais de um procedimento, consideramos tal atitude normal no desenvolvimento da pesquisa, uma vez que os objetivos e o objeto de pesquisa levam o pesquisador a utilizar mais de um procedimento para compreender o fenômeno investigado. Vale ressaltar nesse estudo que uma mesma pesquisa pode utilizar mais de um paradigma, técnica ou instrumento. A utilização simultânea e coletiva destes elementos é que vai garantir o êxito e a eficácia das produções acadêmicas.

\section{REFERÊNCIAS}

ALAMI, Sophie, DESJEUX, Dominique, MOUSSAOUI-GARABUAU, Isabelle. Os métodos qualitativos. Petrópolis, RJ : Vozes, 2010.

ALBERTI, V. História oral : a experiência do CPDOC. Rio de Janeiro: Fundação Getúlio Vargas, 1990.

BARDIN, I. Análise do Conteúdo. Lisboa: Edições, 1979.

BOGDAN, R. BIKLEN. S. Investigação qualitativa em educação: Uma introdução à teoria e aos métodos. Porto, Portugal: Porto Editora, 1994. 
COELHO FILHO, Mateus de Souza. GONZAGA, Amarildo Menezes. Iniciação científica na formação de professores : Contribuições Epistemológicas. 1 ed. Curitiba :Appris, 2013.

CRESWELL, John W. Projeto de pesquisa: método qualitativo, quantitativo e misto. Tradução Magad Lopes; consultoria, supervisão e revisão técnica desta edição Dirceu da Silva. 3. ed. Porto Alegre : Artmed, 2010.

FONSECA, J. J. S. Metodologia da pesquisa científica. Fortaleza: UEC, 2002. Apostila.

GALlianO, A. G. Método Científico:teoria e prática. São Paulo: Harba, 1986.

GALIAZZI, Maria do Carmo. Educar pela pesquisa:ambiente de formação de professores de ciências. Ijuí : Unijuí, 2011.

GATTI, Angelina Bernadete. Grupo focal em ciência sociais e humanas. Brasília :Liber Livro Editora, 2005.

GHEDIN, Evandro, FRANCO, Maria Amélia Santoro. Questões de método na construção da pesquisa em Educação. 2 ed. São Paulo : Cortez, 2011.

GIL, Antônio. Carlos. Métodos e técnicas de pesquisa social. 6. ed. São Paulo : Atlas, 2008.

LAKATOS, Eva Maria, MARCONI, Fundamentos da metodologia científica. 7. ed. São Paulo: Atlas, 2010.

MORAES, Roque, GALIAZZI, Maria do Carmo. Análise textual discursiva. 2 ed. rev. Ijuí : Unijuí, 2011.

OLIVEIRA, Maria Marly de Oliveira. Como fazer pesquisa qualitativa. Rio de Janeiro: Vozes, 2007.

PRODANOV,Cleber Alfonso Cristiano, FREITAS, Ernani Cesar de. Metodologia do trabalho científico: Métodos e Técnicas da Pesquisa e do Trabalho Acadêmico [recurso eletrônico]. 1. ed. Novo Hamburgo :Feevale, 2013.

SEVERINO, Antônio Joaquim. Metodologia do trabalho científico. 23. ed. rev. e atual. São Paulo : Cortez, 2007.

THIOLLENT, Michel. Crítica metodológica, investigação social e enquete operária. São Paulo : Polis (1982).

TRUJILLO FERRARI, Afonso. Metodologia da pesquisa científica. São Paulo: McGrawHill do Brasil, 1982. 